\title{
O clítico e seu status prosódico*
}

\author{
Leda Bisol \\ Pontifícia Universidade Católica do Rio Grande do Sul
}

\section{Abstract}

Clitics have received great attention in recent years. Articles dealing with their syntactic or prosodic structure enrich the literature. But the question we are raising here is about where clitics take prosodic status. Is it in the lexical or in the postlexical component? We will argue that clitics are prosodized in the postlexical component. Arguments will be provided for the difference between the prefix that belongs to the Phonological Word formed in the lexical component and the clitic that belongs to the Clitic Group. The most important evidence that supports the idea that the clitic does not belong to the phonological word comes from Elision, a sandhi rule, that applies between words including clitics. 


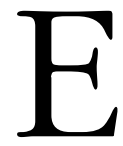

ste estudo desenvolve-se em torno da idéia de que o clítico com a palavra de conteúdo adjacente forma a primeira categoria prosódica pós-lexical. Chamemo-la grupo clítico ou palavra fonológica pós-lexical, é um constituinte diretamente derivado da sintaxe que se distingue da palavra fonológica, tradicionalmente identificada pelo acento.

\section{TEORIAS PROSÓDICAS}

A hipótese de que a relação entre sintaxe e fonologia se faz indiretamente dispõe de dois modelos teóricos: a teoria baseada em bordas (End-base) e a teoria relacional. A primeira, assinada por SELKIRK (1986) e SELKIRK \& SHEN (1990) entre outros, define os domínios prosódicos através de limites de constituintes sintáticos do tipo X-barra; a segunda, que leva os nomes de NESPOR \& VOGEL (1986), ocupa-se da organização dos constituintes prosódicos, a partir de cabeças lexicais.

Para Selkirk, a única referência à estrutura sintática necessária à estrutura prosódica é o limite direito/esquerdo dos constituintes sintáticos do tipo X-barra. O que fica entre essas bordas é um domínio prosódico. Para Nespor e Vogel, importa identificar o cabeça lexical, início de um constituinte.

\subsection{Teoria baseada em bordas}

Na proposta conhecida por End-base, versão (1986), Selkirk deixa de lado a sílaba e o pé porque não figuram apenas como domínios prosódicos, pois muitas vezes são partes constitutivas de regras lexicais. Também a frase entonacional não é considerada, em 
virtude de seus compromissos semânticos ou pragmáticos. Uma cadeia de palavras é, pois, escandida em dois domínios: a palavra prosódica e a frase fonológica que, na verdade, são frases de tamanhos diferentes. Ficam incluídos no domínio da palavra prosódica: a palavra fonológica, tradicionalmente identificada por apenas um acento primário, as palavras funcionais que lhe dizem respeito, incluindo os clíticos. Palavras funcionais, ramificadas ou não, são invisíveis às regras que derivam domínios prosódicos (SELKIRK, 1986:396). Assim, no exemplo abaixo, existem quatro palavras prosódicas e três frases fonológicas.
(1) Aquelas meninas
apanharam
todas as rosas
do jardim
a. (
b. (
)
) (

)
) $\omega$

O complemento (argumento) que segue imediatamente um cabeça lexical, como todas as rosas em (lb), é incluído no domínio derivado da frase com esse cabeça, enquanto o segundo complemento nunca estará no mesmo domínio do primeiro (SELKIRK, 1986:390). Adjetivos são interpretados conforme sua posição em relação ao nome. Assim em (2a), grande e artista formam um só constituinte, pois adjetivos restritivos, antepostos a um cabeça, assim como os especificadores, não são vistos como projeções máximas; mas em (2b), famoso, um adjetivo posposto forma um constituinte à parte.

(2) a. Aquelas meninas conheceram o grande artista

$\begin{array}{llllll}( & ) & ( & & ( & \\ ( & ) & ( & \end{array}$

b. Aquelas meninas conheceram o artista famoso.

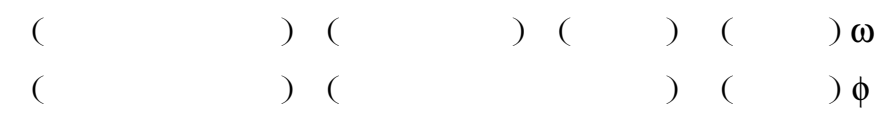

Por maior poder explicativo que tenha esse modelo, cria ele um embaraço para a descrição de línguas que projetam o grupo 
clítico como domínio de regras: o clítico e a palavra de conteúdo adjacente ficam incluídos na palavra prosódica, que pode ter diferentes tamanhos. Tanto aquela menina é uma palavra prosódica quanto a menina ou deixa-me. Estamos certos de que o grupo clítico não se confunde com nenhuma das duas unidades prosódicas supracitadas.

\subsection{Teoria relacional}

Os constituintes prosódicos de uma cadeia de palavras criamse, segundo Nespor e Vogel, através da relação forte/fraco ou viceversa, que se estabelece entre um cabeça lexical, projetado por uma árvore sintática do tipo X-barra e todos os elementos que ficam sob o domínio do mesmo nó.

Esses domínios entram em relação hierárquica, de acordo com Strict Layer Hypothesis (SELKIK, 1984; NESPOR \& VOGEL, 1986), segundo a qual toda unidade prosodicamente segmentada deve ser incorporada à unidade imediatamente superior. Isto é, sem constituir ninhos dentro de outros ninhos, cada nível hierárquico faz parte do nível imediatamente superior.

(3) Hierarquia Prosódica (HP)
a. Enunciado
b. Frase entonacional
c. Frase fonológica
d. Grupo clítico
e. Palavra fonológica
f. Pé
g. Sílaba

Embora não tenham estabelecido explicitamente uma divisão entre constituintes prosódicos abaixo e acima da palavra, estão incluídos na proposta constituintes lexicais e pós-lexicais.

Retomando os exemplos de (1) e (2) para apreciar as diferenças, teríamos na visão de Nespor e Vogel os seguintes domínios: 
(4) a. Aquelas meninas apanharam todas as rosas do jardim.

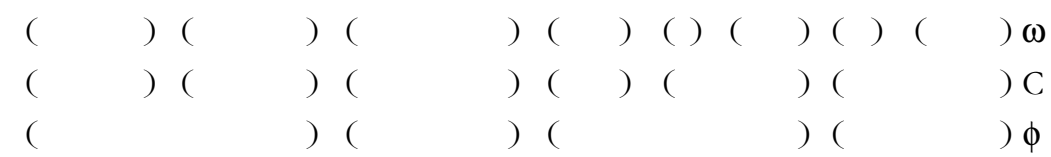

b. Aquelas meninas conheceram o artista famoso.

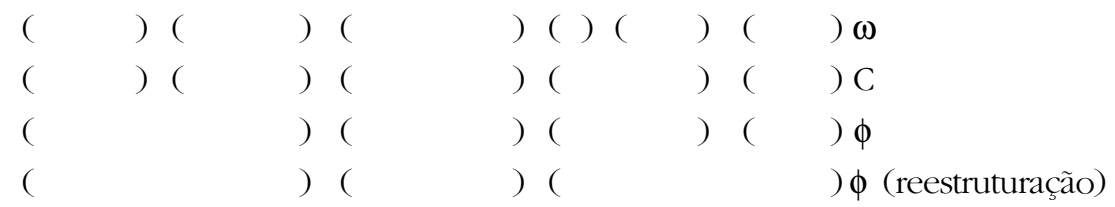

A palavra fonológica, na acepção de Nespor e Vogel, identificase por não ter mais do que um acento primário. E, se todo n consiste de n-1, é preciso que o clítico figure como palavra prosódica em (3), embora como forma marcada.

No nível imediatamente mais alto, uma palavra lexical com seus clíticos é um grupo clítico (C), assim como toda palavra fonológica passa a sê-lo, em função de Strict Layer Hypothesis.

Por outro lado, uma frase (3c) compõe-se de um cabeça, precedido de todos os clíticos ou palavras funcionais que lhe dizem respeito, incluindo os adjetivos antepostos. Um adjetivo posposto por si só forma uma frase, mas pode ser reincorporado ao constituinte precedente por reestruturação.

A reestruturação consiste em juntar a uma frase o primeiro complemento de X que esteja em seu lado recursivo (NESPOR \& VOGEL, 1986:173). É uma questão paramétrica ser esse complemento ramificado ou não. ${ }^{1}$

Como vemos, os limites da frase e da palavra fonológica nem sempre coincidem nas duas propostas.

Essa teoria que considera o grupo clítico um domínio prosódico, ponto de vista que dirige este estudo, tem, todavia, a desvantagem, em razão do caráter escalar da hierarquia prosódica, de atribuir, por marca, ao clítico um status que ele não tem no componente lexical: o de palavra fonológica. 


\section{O TEMA}

Clíticos são formativos difíceis de classificar como palavras independentes ou afixos. Diferem da palavra independente, porque não são candidatos a receber acento; diferem de afixos flexionais, pois são formas livres; diferem de afixos derivativos, porque são necessariamente periféricos ${ }^{2}$. Prosodicamente identificados como elementos fracos, são encontrados em diferentes categorias:

(5) Pedro é forte (verbo $)^{3}$

Vou para casa (preposição)

Pedro toca piano, mas João toca violino (conjunção)

Ganhou uma bicicleta (determinativo)

Vejo-te amanhã (pronome)

Alguns têm mobilidade como os pronominais; outros são posicionalmente fixos como os artigos. Em línguas românicas, por exemplo, os pronomes átonos podem ser proclíticos ou enclíticos:

(6) Para dizer-lhe a verdade

Para the dizer a verdade

Ci vidiamo domani (italiano)

Vidiamoci domani

Juan los queria invitar (espanhol)

Juan queria invitarlos

Muitas vezes o uso enclítico ou proclítico é dirigido por restrições sintáticas, as quais tendem a não vigorar no português brasileiro que privilegia a próclise. O imperativo, por exemplo, prefere de modo geral o pronome enclítico e o proclítico prevalece em orações subordinadas:

(7) Dá-me este livro (português europeu)

Disegnamelo, ti prego (italiano)

Espero que nos reencontremos na festa de Maria ${ }^{4}$ 
Vale observar que é comum palavras funcionais acentuadas perderem o acento, comportando-se como clíticos (8a), como também itens lexicais de pouca substância fonética aparecerem cliticizados (8b).

(8) a. de minhavontade versus de minhavontade rde mia vontade

$\begin{array}{lllllllllllllllll}2 & 1 & 3 & 2 & 1 & 3 & 2 & 2 & 3 & 2 & 1 & 3 & 2 & 2 & 2 & 1 & 3\end{array}$

b. Samba é vida versus sam [be] vida

$\begin{array}{lllllllll}1 & 3 & 1 & 1 & 3 & 1 & 2 & 2 & 3\end{array}$

onde 1 está por tônica, 2 por pretônica e 3 postônica, segundo a pauta prosódica de Mattoso Câmara.

Os clíticos podem receber acento enfático como qualquer sílaba de uma cadeia de fala. Não se trata, porém, de acento primário, lexical, que identifica a palavra fonológica. Outros aspectos mereceriam ponderações, como a diferença entre clíticos pronominais, determinativos e complementizadores, e o tipo de sintaxe que os envolve, no entanto os analisaremos somente à luz da seguinte questão: em que nível o clítico adquire status prosódico?

\section{A PROPOSTA}

Os argumentos que serão apresentados sustentam a idéia, defendida por NESPOR \& VOGEL (1986) e HAYES (1989) de que o clítico com o seu hospedeiro formam um constituinte prosódico. Mas o ponto em questão é a natureza frasal desse constituinte, que motiva a hipótese de que o clítico é invisível à palavra fonológica que se forma no componente lexical, atingindo status prosódico, afora o de sílaba, somente depois de ter assumido um papel sintático. O grupo clítico é o menor constituinte pós-lexical. 


\section{A ANÁLISE}

Porque o grupo clítico na visão de Nespor e Vogel se coloca na hierarquia prosódica entre a frase e a palavra fonológica (3), tentaremos definir as três categorias à luz dessa teoria, começando pela frase, seguindo-se a palavra e, por fim, o tema de estudo.

\subsection{A frase fonológica $(\phi)$}

Na linha de Nespor e Vogel, a frase fonológica é entendida como um cabeça lexical $\mathrm{X}$ e todos os elementos que ficam em seu lado não-recursivo, dentro de X-max.

Identificados os cabeças como $\mathrm{N}, \mathrm{V}$ e A, a frase fonológica do português, com recursividade à direita, organiza-se metricamente com um dos cabeças supracitados à direita, e todos os recessivos que ficam à sua esquerda, o lado não-recursivo, dentro do mesmo domínio de X barra.

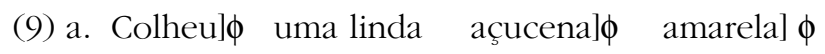

b. Colheul $\phi$ uma linda açucena amarela] $\phi$ (por reestruturação)

Há três frases fonológicas em (9a), pois, como vimos em páginas precedentes, somente o adjetivo posposto e não o anteposto ao nome projeta-se como cabeça de constituinte, enquanto há duas em (9b), por reestruturação.

Definida a frase fonológica, mais detalhes não se fazem necessários para o objetivo em foco, voltado para o nível que entre essa e a palavra se coloca.

\subsection{A palavra fonológica (w)}

Em HP, a palavra fonológica domina o pé. Isso significa que, entre as sílabas que a compõem, existe uma relação de dominância no sentido de que apenas uma delas, candidata ao acento, é forte ou dominante e todas as outras são fracas ou recessivas. Se a palavra possuir mais de um pé, o pé mais à direita é o dominante, em se 
tratando de línguas com recursividade à direita, como o português, e todos os demais são relativamente fracos, de acordo com o princípio de Proeminência Relativa (LIBERMAN \& PRINCE, 1977).

Em Português, a palavra fonológica pode coincidir com os elementos terminais de uma árvore sintática, incluindo a raiz e todos os seus afixos; longe, porém, de ser regra geral, haja vista o composto que, ligado sintaticamente apenas a um nó terminal, compreende duas ou mais palavras fonológicas.

Por outro lado, há lexemas que ora têm autonomia ora não. Referimo-nos a certos prefixos. Observemos (10), levando em conta as variedades do português brasileiro que, em posição pretônica, com algumas exceções, não possuem vogais médias baixas, porque são neutralizadas, como ocorre no dialeto carioca, descrito por Câmara e nos falares de estados circunvizinhos, estendendo-se até o extremo sul.

(10) a. Forma presa

i) $\operatorname{pr\varepsilon }+$ fixo $>$ prefixo

pre+tonica $>$ pretônica

pre+sentir $>$ pressentir

pre+dispor $>$ predispor

pre+conceber $>$ preconceber

ii) pos+fácio (latim, fatio) > posfácio

pos+por

$>$ pospor

pos+ponto

pos+posição

pos+céfalo
$>$ posponto

$>$ posposição

$>$ poscéfalo b. Forma livre

i) pre+estréia $>$ pre-estréia

pre+diluviano $>$ pre-diluviano

pre+escola $>$ pre-escola

pre+fala $>$ pre-fala

pre+coma $>$ pre-coma

ii) pos+lexical > pos-lexical pos+doutorado $>$ pos-doutorado pos+guerra $>$ pos-guerra pos+textual $>$ pos-textual pos+operatório > pos-operatório iii) proclise (pref. do grego) prologo (idem) progresso (pref. do latim) iii) pro+reitor $>$ pro-reitor

pro+social $>$ pro-social

pro+americano $>$ pro-americano os pros (os contras) 
Em (10a,i), o prefixo pre com o sentido geral de anterioridade, sem autonomia, sofre a regra de neutralização, $(\varepsilon>e)$, como sílaba pretônica de uma palavra; em (10b,i), ao contrário, com autonomia, comporta-se como membro de um composto, com o sentido de estágio precedente; não sofre a regra de neutralização e tem acento próprio. Da mesma forma, o prefixo pos, com o sentido geral de posterioridade, em (10a,ii), é meramente sílaba pretônica, sujeita à neutralização, ( 0 >o), mas em (10b, ii), quando a idéia de estágio ou grau separado prevalece, é membro de um composto. Já o prefixo pro depende de sua origem e sentido. O que vem de um radical grego com a acepção de anterior ou antecipado incorporou-se de todo a uma raiz para com ela formar um vocábulo, atraindo o acento, (10a,iii), assim como o que veio do latim ajustado a uma palavra com o sentido de movimento para a frente, exemplificado nesta coluna que, diferentemente, não atrai o acento.

Vale notar que o português brasileiro mantém fixa uma pauta pretônica de cinco vogais /i, e, a, o, u/. As vogais / $0 \varepsilon /$ somente ocorrem na pauta tônica e são neutralizadas na pretônica. Nela pode ocorrer variavelmente a harmonia vocálica, em função da presença de uma vogal alta na sílaba seguinte, menino minino, coruja c curuja, todavia, sem efeitos de neutralização.

Os exemplos em (10) sugerem que os prefixos são susceptíveis de serem separados em dois grupos, tomando-se o acento como um dos indícios de sua autonomia. Os que exibem acento próprio comportam-se como membros de palavras compostas, enquanto os demais são anexados a uma base morfológica. Entre esses há os que se integram à palavra fonológica no primeiro nível do componente lexical, pois não alteram estruturas prosódicas prévias como (11a) e outros que, seja em virtude do Princípio de Integridade, (HARRIS, 1983), que proíbe no léxico desmanchar estruturas prosódicas de palavras prontas, seja em virtude de não necessitarem ligação direta à base morfológica, integram-se mais tardiamente à palavra fonológica (11b). ${ }^{5}$ Isso acontece com o prefixo des- como em delzarlmar, por exemplo, em que a ressilabação converte a coda em 
ataque; e em variantes do tipo relelxame re[i]xame, que estão a indicar que a regra fonética que levanta /e/ inicial antes de $/ \mathrm{N} / \mathrm{e}$ /S/ aplica-se antes da ressilabação.

(11) in+stável > instável; des+armar > de[zar]mar; re+exame > reexame $\sim$ re[i]xame.

Componente lexical:

Morfologia

Prefixação

a.

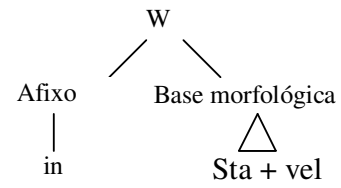

b.

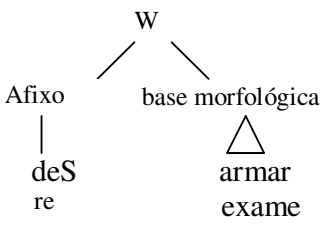

c. Composição

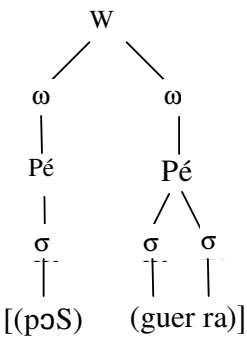

Fonologia

Silabação

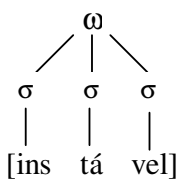

Silabação

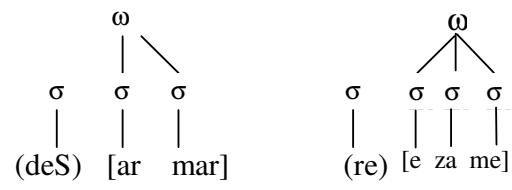

Componente Pós-lexical

Elev. opc. [i.za.mi]

Ressilabação
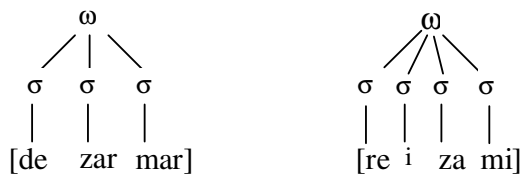

uma palavra lexical

duas palavras fonológicas 
A prefixação é um processo morfológico que sempre implica silabação, um processo fonológico que, preenchidas as condições, origina a palavra fonológica.

Prefixação e composição são processos diferentes. O primeiro cria uma palavra fonológica como instável e reexame; e o segundo, duas ou mais como porta-bandeira e pós-guerra.

(12) Uma palavra fonológica borboleta

pérola

reitor

prefácio

postônico
Duas palavras fonológicas

guarda-chuva

porta-bandeira

pró-reitor

pré-coma

pós-doutorado

Entre os prefixos existem aqueles que tendem exclusivamente a funcionar como afixos: re-, rebater, reformular e a-amoral, aterrorizar, des- desmontar e há os que ficam entre dois caminhos: o de forma livre e o de forma presa, como pós, já citado, uma variante da preposição após. Enquanto pós-lexical se mostra invariante, postônico tem na fala a variante pós-tônico, como se a fase de mudança, caracterizada pela presença de variantes, ainda estivesse viva, e a palavra como um todo não tivesse sido lexicalizada.

O ponto em questão é o fato de que prefixos sem autonomia não se confundem com os clíticos. Aqueles fazem parte da palavra fonológica, depois de terem sido anexados a uma base morfológica. Todos, sem exceção, integram a palavra fonológica que ajudam a construir. Clíticos anexam-se diretamente a uma palavra fonológica bem formada, sem integrá-la, como veremos mais adiante.

Por fim chamamos atenção para o fato de que, na estrutura da palavra fonológica, entram três elementos: sílaba, pé e acento. Todavia é a presença do acento o seu identificador principal, pois palavras que não satisfazem a condição mínima de pé são encontradas em muitas línguas. 


\subsection{A palavra mínima}

Parece que o português não possui a síndrome da palavra mínima, entendida essa como bimórica ou dissílaba, no sentido de que toda palavra conteria minimamente um pé com duas moras. Ao lado de monossílabos tônicos de sílaba pesada (13a), figuram monossílabos tônicos de sílaba leve (13b,c,d), que não satisfazem essa condição.

(13) Monossílabos tônicos

$\begin{array}{cccc}\text { a. CVC } & \text { b. CV(V.média baixa) } & \text { c. CV (V.baixa) } & \text { d. CV(V.alta) } \\ \text { três } & \text { pe } & \text { chá } & \text { mi (nota musical) } \\ \text { dor } & \text { do } & \text { pá } & \text { si (nota musical) } \\ \text { mês } & \text { fe } & \text { má } & \text { nu (adj) } \\ \text { sol } & \text { po } & \text { cá (adv) } & \text { cru (adj) } \\ \text { pai } & \text { so } & \text { fá } & \text { ti (pron) } \\ \text { cruz } & \text { no } & \text { lá (adv) } & \text { tu (pron) }\end{array}$

Em português, a palavra mínima pode ter duas moras ou ser apenas constituída de uma sílaba leve, ou seja, sílaba de rima não ramificada. Observe-se que a vogal nestes casos tanto pode ter sonoridade máxima (13c) ou similar (13b) quanto mínima (13d), de modo que não se pode recorrer à sonoridade em busca de outros esclarecimentos. Sobre essa sílaba incide o acento. Temos, pois, monossílabos tônicos pesados e leves, e os últimos não se valem de nenhum recurso de alongamento para atender ao requisito das duas moras. Também não existe processo fonológico que deixe de ser aplicado para evitar o surgimento de palavras de uma sílaba só e leve. Assim da raiz pe(d) deriva-se pedal, pedestre e pé. E de cha(l), chaleira e chá. Em suma, a menor palavra do português é constituída de apenas uma sílaba sem coda.

Contudo o que identifica a maior parte das palavras do português, independentemente de seu tamanho, é a presença de um pé binário mais à direita, formado de duas sílabas leves, casa, cortina, borboleta, ou de uma sílaba pesada e outra leve, carta, 
bandeira, rebelde. O troqueu mais constante na língua está exemplificado em (14). É a forma não-marcada.

(14) Troqueu silábico

$\begin{array}{ll}\text { gaita } & \text { casa } \\ \text { fardo } & \text { fera } \\ \text { selva } & \text { seda } \\ \text { cadeira } & \text { saudade } \\ \text { rebelde } & \text { borboleta }\end{array}$

Uma evidência de que PB organiza ritmicamente suas silabas em constituintes binários de cabeça à esquerda, destinando acento por peso somente à sílaba final, oferecem-nos as proparoxítonas. Em tais palavras, o acento incide na segunda sílaba, considerando-se extramétrica a sílaba final. O ponto, independentemente da análise que se fizer, é que a fala popular tende a evitá-las, praticando a síncope: ${ }^{6}$

$\begin{array}{llll}\text { (15) fósforo } & >\text { fosfru } & \text { óculos } & >\text { oclus } \\ \text { cárcere } & >\text { carci } & \text { abóbora } & >\text { abobra } \\ \text { árvore } & >\text { arvi } & \text { xícara } & >\text { xicra } \\ \text { máscara } & >\text { mascra } & \text { pétala } & >\text { petla }\end{array}$

Como se vê, não são as moras que, inconscientemente, os falantes contam, mas as sílabas. Por outro lado, é interessante observar que a vogal perdida é justamente a da sílaba fraca de um troqueu, indicada abaixo pelo ponto, ao lado do asterisco que está por sílaba forte. Protegida a última sílaba pela extrametricidade, a sílaba fraca do pé é apagada.
(16) a $\quad \begin{aligned} & (* \\ & \text { fos.fo. }<\text { ro }>\end{aligned}$
b. $\quad$ o. cu. $<\operatorname{los}>$
(* )
car.ce. $<$ re $>$
a. $\stackrel{(*) .)}{\text { bo.bo. }<\text { ra }>}$
(* .)
(* .)
ar.vo. $<$ re $>$
pe.ta. $<$ la $>$ 
Nada justificaria separar (16a) de (16b), levantando um troqueu mórico em função da sílaba pesada no primeiro bloco (fós.) fo. $\langle$ ro $>$ e um troqueu silábico no segundo (ó.cu.) <los $>$. Teríamos de dispor de justificativas distintas para o mesmo caso de apagamento de sílaba, de origem histórica.

Essa digressão sobre a palavra mínima toma sentido se considerarmos que, na classe dos clíticos, há aqueles que formam pés, como para, por, mas, em. Muitos, porém, não atendem a essa restrição como os pronominais me, te, se, the, nos, sem falar em outras palavras funcionais $a, e$, o ou combinações $d a, d o, n o, n a$. O clítico, como vemos, não atende aos requisitos básicos da palavra fonológica, que são pé e/ou acento. Figura no léxico como categoria morfológica, identificada prosodicamente apenas como sílaba.

\subsection{Grupo Clítico (C)}

O clítico e seu hospedeiro mantêm entre si a relação de dominância que define um constituinte prosódico: o cabeça é a palavra de conteúdo e o dominado é um clítico ou mais de um. Mas é um grupo que pressupõe uma origem sintática, como qualquer frase fonológica. É o menor constituinte frasal.

Enquanto os prefixos sempre integram a palavra fonológica, completando-a ou aumentando-a, embora, como vimos, alguns o façam tardiamente, os clíticos anexam-se a uma palavra fonológica pronta, sem integrá-la, emergindo daí o primeiro constituinte prosódico pós-lexical. O processo de integração que existe entre o prefixo e sua base não existe entre o clítico e seu hospedeiro, de modo que os membros que compõem essa unidade mantêm sua independência. Trata-se, independentemente do rótulo, grupo clítico ou palavra fonológica pós-lexical, do menor constituinte prosódico pós-lexical. 
(17)

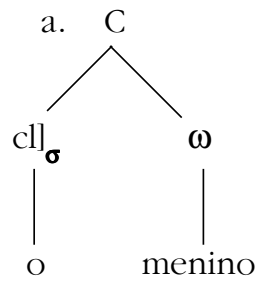

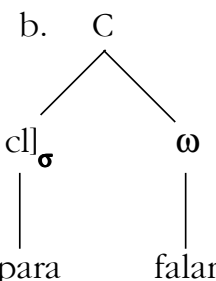
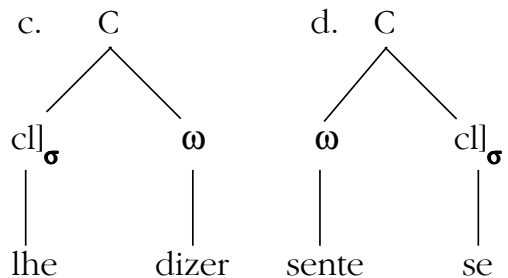

A próclise tende a ser a regra geral $(17 \mathrm{a}, \mathrm{b}, \mathrm{c})$; a ênclise pronominal $(17 \mathrm{~d})$, espelho do esquema anterior, vai-se fazendo rara, embora a escrita ainda a preserve. Referimo-nos ao português brasileiro (PB) e não ao português europeu (PE).

Com respeito à relação com o seu cabeça, mais livre do que a relação prefixal, e mais semelhante a dos elementos que compõem uma frase, os seguintes fatos devem ser ressaltados:

i) Os clíticos figuram como contextos independentes na aplicação de regras fonológicas. A neutralização de /e, o/, em final de palavra, onde /i,u/ respectivamente se manifestam, aplica-se em ambos os membros do grupo, como se aplica em qualquer palavra lexical ou funcional. Isso sugere que entre o clítico e seu cabeça estabelece-se uma relação de adjunção e não de integridade.

$\begin{array}{lll}\text { (18) menino } & > & \text { du meninu } \\ \text { de ferro } & > & \text { di ferru } \\ \text { me leve } & > & \text { mi levi } \\ \text { leve-me } & > & \text { levi-mi } \\ \text { sente-se } & > & \text { senti-si } \\ \text { se sente } & > & \text { si senti }\end{array}$

Interessante observar que o clítico, esteja em próclise esteja em ênclise, fica sensível à regra, permitindo desambigüizar pares mínimos, como foi apontado por CÂMARA (1970):
(19) por tela
[pur] tela
opondo-se a portela
se senta
[si] senta
opondo-se a sessenta. 
Prefixos ou sílabas pretônicas, integrados a seu hospedeiro, desconhecem esse tipo de levantamento:

(20) a. prefixos

$\begin{array}{ll}\text { preconceber } & \text { *priconceber } \\ \text { reanimar } & \text { *rianimar } \\ \text { pospor } & \text { *puspor }\end{array}$

b. não prefixos

$\begin{array}{ll}\text { lotação } & \text { *lutação } \\ \text { rodar } & \text { *rudar } \\ \text { perene } & \text { *pirene }\end{array}$

ii) Clíticos são insensíveis a regras que se esperariam neles fossem aplicadas.

Prefixos como qualquer sílaba pretônica sofrem a neutralização da vogal média baixa, como vimos em (10), grosseiramente representada em (21).

$$
\begin{array}{lll}
/ \varepsilon, \mathrm{o} / \rightarrow & [\mathrm{e}, \mathrm{o}] /-] \omega \\
& > & \text { soláço } \\
\text { Sol }] & > & \text { beléza } \\
\text { bela } & > & \text { pospónto } \\
\text { posponto } &
\end{array}
$$

Clíticos, que não possuem vogais médias baixas porque inacentuados, também poderiam oferecer contexto a (21), quando derivados de itens lexicais, como o verbo ser na forma é em (22). Todavia ficam diante dela insensíveis:

$$
\begin{array}{cccccccc}
\text { Samba } & \text { é } & \text { vida } & \rightarrow & \text { sam [be] vida } & \text { (cliticização) } \\
1 & 3 & 1 & 13 & & 1 & 2 & 13
\end{array}
$$

iii) Clíticos, ainda que inseridos na palavra precedente, preferem a próclise.

Quando duas palavras entram em choque, em razão do contato de duas vogais, a nova sílaba que se forma dá preferência a ajustarse à pauta pretônica da palavra seguinte. Isso tanto ocorre entre duas palavras lexicais, como em (23a), quanto com clíticos (23b,c). 


\begin{tabular}{|c|c|c|c|c|}
\hline (23) a. & casa escura & $>$ & $\begin{array}{c}\text { ca[zis]cura } \\
\begin{array}{lll}12 & 13\end{array}\end{array}$ & $\begin{array}{c}\text { ?ca[zis]cura } \\
1313\end{array}$ \\
\hline b. & avisa os vizinhos & $>$ & $\begin{array}{l}\text { a vi [zus]vi zi nhos } \\
\begin{array}{llllll}2 & 1 & 2 & 2 & 2\end{array}\end{array}$ & $\begin{array}{l}\text { ?a vi [zus] vi zi nhos } \\
\begin{array}{ccccc}2 & 1 & 3 & 2\end{array}\end{array}$ \\
\hline c. & lava e lubrifica & $>$ & la [vi] lu bri fi ca & ? la [vi] lu bri fi ca \\
\hline & & & $\begin{array}{llllll}1 & 2 & 2 & 2 & 1 & 3\end{array}$ & $\begin{array}{llllll}1 & 3 & 2 & 2 & 1 & 3\end{array}$ \\
\hline
\end{tabular}

A interrogação em (23) indica que a segunda variante se faz mais rara.

Ainda que relacionado, em termos de constituinte, à palavra seguinte, clíticos $(23 \mathrm{~b}, \mathrm{c})$ podem ligar-se foneticamente à palavra à esquerda, mantendo, porém, inalterável a sua força de intensidade relativa à pauta pretônica. É somente por sândi que a integração com a palavra seguinte ocorre. Mas, neste caso, o resultado é uma palavra fonológica que extrapola o tamanho da palavra fonológica, formada no componente lexical.

A idéia que vai conduzindo estas linhas atribui aos clíticos, sem marca de acento, status prosódico próprio somente no pós-léxico, sejam eles pronomes ou complementizadores e tenham sintaxes particulares. Possuir sílaba não lhe confere um status prosódico particular, pois todo segmento de uma cadeia de fala deve, lexical ou pós-lexicalmente, ser silabado.

Uma observação que se deve a MENUZZI \& VIDOR (1999) diz respeito à procliticização do pronome que em interrogativas indiretas: este pronome parece exigir que o clítico esteja sintaticamente adjacente a material fonético à sua direita. Assim (24a) é uma construção malformada, porque existe um vazio sintático entre o clítico e a palavra lexical mais próxima, uma vez que COMP é zero; (24b) está bem formada, porque o verbo subiu para a posição de COMP, preenchendo esse vazio. Seria (24a) aceitável se que fosse acentuado, perdendo sua característica de clítico. 
(24) a. *Ele perguntou que João fez.

b. Ele perguntou que fez João.

a. Estrutura bem formada:

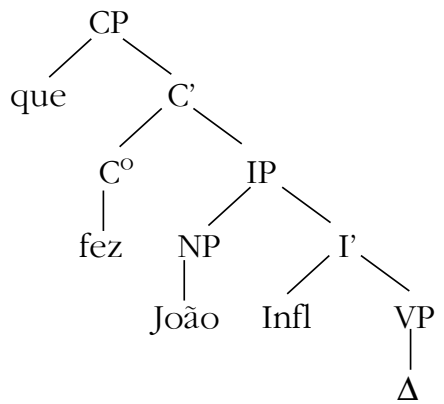

b. Estrutura mal formada

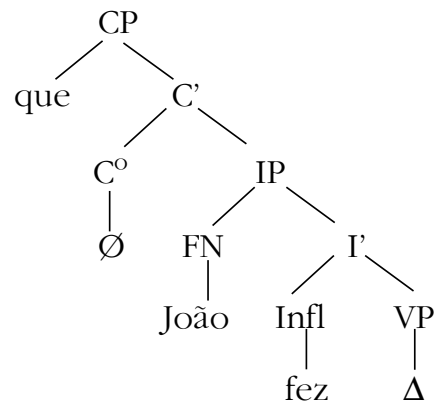

E' bem formada ele perguntou que fez João como seria ele perguntou o que que João fez, mas não: ele perguntou que João fez.

Parece que a condição de adjacência que caracteriza o clítico prosodicamente também se reflete na sintaxe, ressalvadas as diferenças estruturais, embora a informação de que dispomos diga respeito somente a um clítico particular.

Mas retomemos o veio que vem conduzindo estas linhas: à luz da teoria prosódica inicialmente exposta, o ponto a ser salientado é o vazio prosódico do clítico no nível da palavra fonológica versus seu real status prosódico no pós-léxico. Esta análise vem mostrando que é impossível manter consistentemente a hierarquia prosódica, à luz de Strict Layer Hypothesis, pois, como vimos, em PB há palavras fonológicas sem pés e clíticos sem status de palavra fonológica. ${ }^{7}$

Dependente em termos de constituinte, o clítico é morfológica e sintaticamente independente, o que (17) representa, ligando-o diretamente a um nó frasal (C), como se fosse uma locução, e não a uma base morfológica, como os afixos. Vale apontar, mais uma vez, a sua diferença com os prefixos, os quais sempre são ligados primeiramente a uma base morfológica, para somente depois integrarem-se à palavra fonológica como um todo. Clíticos nunca se integram a uma palavra fonológica mas a ela se anexam, por adjunção, 
sob o domínio de um constituinte prosodicamente mais alto. Tratase de um constituinte prosódico que se compõe de uma palavra fonológica e de um ou mais clíticos, fonologicamente silabados.

Contemplemos via Fonologia Lexical, um dos mais interessantes modelos teóricos, o qual divide a fonologia em lexical e pós-lexical, as regras a que os clíticos mostram disponibilidade.

A única regra lexical a que os clíticos poderiam estar expostos, em PB, é a neutralização da pretônica, já referida. ${ }^{8}$ Mas ficam eles invisíveis a essa regra, representada em (21), assim como à atribuição de acento primário, porque são por natureza átonos.

Alguns são nasalizados como em, com e sem. Mas a nasalidade fonológica, na linha de Mattoso Câmara, fica garantida no componente lexical pela seqüência VN, uma vogal oral seguida de um segmento nasal, subespecificado, que se opõe V: /seNda/versus / seda/, razão pela qual a gramática mais simples a ignora no nível lexical cíclico. O preenchimento de $\mathrm{N}$ que apresenta variantes, manifestando-se ora com os pontos de articulação da oclusiva seguinte ora com os da vogal precedente, sobretudo se a consoante seguinte for [+cont] ou vazio, ou ainda, reduzindo-se a zero, são opções. Regras com alofones são pós-lexicais.

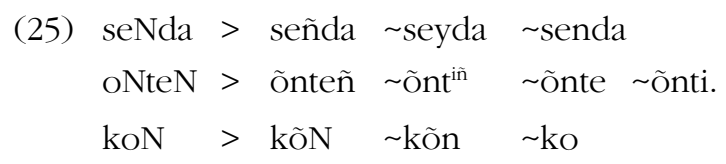

E referindo uma peculiaridade do acento, clíticos são insensíveis à restrição das três janelas, comum às línguas românicas, como espanhol e italiano, segundo a qual o acento não vai além da terceira sílaba a contar da direita. Há filó, cása, lámpada e relámpago. Mas não rélampago. No entanto no grupo verbo e seu clítico encontramse dávamos-lhe, contávamos-lhe, considerávamo-lo, com acento na quarta sílaba, em princípio proibido na língua. No entanto essas formas existem, apesar da restrição mencionada, indicando que sua formação implica alguma sintaxe de frase, posterior à atribuição do acento. 
Ficam expostos, pois, somente a regras fonológicas pós-lexicais:

A primeira, já comentada, é a neutralização da átona final, uma regra variável: senti-se $\sim$ sente-se $\sim$ sente-si $\sim$ senti-si.

Há dialetos geográficos que não praticam essa regra ou a praticam variavelmente, o que permite afirmar que a neutralização da átona final somente se aplica no pós-léxico.

As três outras, também pós-lexicais, são, recapitulando, a nasalização da vogal, o preenchimento de N, a que alguns clíticos estão sujeitos e a proclitização da sílaba resultante do sândi.

Até esse ponto, temos, em resumo, as seguintes evidências que argumentam em favor da hipótese de que o clítico assume, somente com o seu hospedeiro, no pós-léxico o seu real status prosódico: i) a insensibilidade à restrição das três janelas; ii) a mobilidade na frase, em se tratando de pronominais; iii) a sensibilidade a regras póslexicais. A primeira distingue-o da palavra fonológica; a segunda aponta-lhe características rítmicas, próprias de constituintes frasais; e a terceira diz respeito a regras que pressupõem esteja pronta a estrutura sintática.

Todavia são as regras de sândi que oferecem o argumento decisivo.

O português brasileiro conhece o sândi como regra geral em todas as suas variedades geográficas, na forma de ditongação, degeminação e elisão da vogal baixa. Para os objetivos deste estudo, consideremos as duas últimas:

(26) Degeminação

a. vocábulo

reestabelecer $\sim$ restabelecer
arqui-inimigo $\sim$ arquinimigo
coordenar $\sim$ cordenar

E também sem fronteiras, i.é, sem o contexto de sândi

álcool álcol

apreensível $\sim$ aprensível

compreender $\sim$ compreender 
b. clítico

que esperança [kis]perança

do oceano [do]ceano

da Amélia [da]mélia

ele se esquece [sis]quece

c. frase

casa amarela ca[za]marela

noite escura noi[tis]cura

vestido usado vesti[du]sado

A degeminação, que consiste na perda de uma sílaba e fusão de vogais idênticas, aplica-se no interior do vocábulo, independentemente de tratar-se de um prefixo de caráter composicional e de estar no contexto de fronteiras morfológicas (26a); aplica-se entre o clítico e a palavra adjacente (26b), dentro de uma frase (26c), ou entre entidades prosódicas maiores, que deixamos de lado. Observemos a elisão.

(27) Elisão

a. frase

menina orgulhosa meni[nor]gulhosa

menina humilde meni[nu]milde

casa escura ca[zis]cura

b. clítico

É uma hotelaria u[mo]telaria

Olhe para o lado pa[ru]lado

Venho pela estrada pe[lis]trada

Em cada esquina ca[dis]quina

c. palavra

para-estatal $\sim$ parestatal

intra-ocular $\sim$ introcular

intra-uterino $\sim$ intruterino 


$\begin{array}{llll}\text { Mas não: } & & \\ \text { maometano } & \text { *mometano } & \text { saideira } & \text { *sideira } \\ \text { alaudista } & \text { *aludista } & \text { paetê } & \text { *petê } \\ \text { taoísmo } & \text { *toísmo } & \text { baobá } & \text { *bobá } \\ \text { gauchada } & \text { *guchada } & \text { baunilha } & \text { *bunilha }\end{array}$

A elisão, que no português brasileiro consiste no apagamento da vogal $a$, quando seguida de outra vogal, que não seja $a$, aplicase dentro de uma frase (27a) e entre o clítico e a palavra lexical (27b), mas não se aplica no interior de um vocábulo sem fronteira morfológica $(27 \mathrm{c})$. Trata-se exclusivamente de sândi, diferentemente da degeminação, que se aplica também sem fronteira morfológica.

Ora, se a elisão ocorre entre o clítico e a palavra de conteúdo com que se relaciona, da mesma forma que ocorre entre qualquer palavra lexical ou funcional, exclusivamente em contexto frasal, estamos admitindo o caráter composicional dos prefixos exemplificados, - então o grupo clítico tem as propriedades de uma frase, por menor que seja. É indubitavelmente um constituinte pós-lexical. ${ }^{9}$

Não tem o tamanho da palavra prosódica de Selkirk. Tem, sim, o tamanho do grupo clítico de Nespor e Vogel, mas diferentemente não está totalmente incluído no nível imediatamente inferior de HP. Seja denominado grupo clítico ou palavra fonológica pós-lexical, trata-se, por sua natureza frasal, de uma locução, pois envolve elementos fonologicamente independentes. Eis aí a menor unidade prosódica do componente pós-lexical.

A palavra, diz ZEC (1993:366-367), é o ponto de intersecção entre os dois componentes. Há línguas que a criam no léxico, outras que a criam no pós-léxico e outras que a têm nos dois componentes, mas com tamanhos diferentes. Os dialetos sérvio-croatas são citados como exemplos de uma e outra. É, pois, entre os que possuem os dois tipos de palavras que se coloca o português brasileiro. Há regras que dizem respeito à palavra fonológica lexical como a metafonia verbal, fer $+i+o>$ firo e a neutralização da pretônica; há as que dizem respeito à palavra fonológica pós-lexical como a neutralização da postônica e o sândi externo. 
Tomando-se a palavra fonológica pós-lexical como o menor domínio de aplicação da elisão e o enunciado como o maior, então a hipótese do Domínio Forte (KIPARSKY, 1984) explica por que ela se aplica em todos os domínios pós-lexicais, do maior ao menor, ou seja, do enunciado ao grupo clítico, ignorando a palavra fonológica. A hipótese faz a seguinte afirmação:

(28) Strong Domain Hypothesis: If a rule applies at level n, it also applies at level $\mathrm{n}-1$, but not necessarily vice-versa.

A elisão, diferentemente da degeminação, abrange todos os domínios prosódicos do pós-léxico, do maior ao menor, manifestandose exclusivamente como sândi. Eis aí um argumento seguro para sustentar a hipótese da prosodização do clítico em nível pós-lexical. ${ }^{10}$

EM SUMA, o presente estudo, que teve o clítico por foco, apresentou evidências de que ele não faz parte da palavra fonológica lexical, mas constitui com a palavra de conteúdo com que se relaciona um constituinte prosódico pós-lexical.

\section{NOTAS}

* Agradeço as observações de dois revisores anônimos que trouxeram importantes esclarecimentos. A responsabilidade dos erros cabe exclusivamente a mim.

${ }^{1}$ Ver BICKMORE (1990) para as possibilidades lógicas de reestruturação em Seikirk e Nespor e Vogel.

${ }^{2}$ Aparecem no interior de formas de futuro, falhar-lhe-ei, falar-lhe-ia, mas essas, sincrônica e diacronicamente, são consideradas conjugações perifrásticas.

${ }^{3}$ Dependendo da pauta acentual, é, verbo ser, pode tornar-se um clítico.

${ }^{4}$ Em se tratando do português brasileiro, estudos quantitativos vêm dando conta da variação existente.

${ }^{5}$ Para maiores informações sobre prefixação e seu envolvimento com fonologia,ver Schwindt (2000).

${ }^{6}$ Sobre proparoxítonas, ver Amaral (2000).

${ }^{7}$ Ver a proposta de Hierarquia Prosódica de Fudge (1999). 
${ }^{8}$ Poder-se-ia considerar lexical a neutralização da pretônica porque nos dilaetos de PB em que os dados deste texto se firmam é regra geral, com algumas exceções como a de não se aplicar diante do -íssimo.

9 É também o domínio exclusivo de elisão de /e/ ou fusão que ocorre no pósléxico entre palavras funcionais.

de+o $>$ do; de+a $>$ da

de+este> deste; de+esta $>$ desta

em+este> neste; em +esta> nesta

de+ele> dele; de+ela> dela

de+aquele> daquele; de+aquela $>$ daquela

${ }^{10}$ Tomamos conhecimento do interessante artigo de Vigário (1997) sobre o status do clítico no português europeu, quando este estudo estava em sua versão final. Defendendo ponto de vista similar quanto à prosodização do clítico no pós-léxico, a análise diversifica-se em vários aspectos, como na linha condutora do trabalho e na argumentação.

\section{REFERÊNCIAS BIBLIOGRÁFICAS}

AMARAL, M. P. do. As proparoxítonas: teoria e variação. Porto Alegre: PUCRS, 2000. (Tese de Doutorado).

BICKMORE, L. Branching nodes and prosodic categories. In INKELAS, S., ZEC, D. (Org.) The Phonology-Syntax connection. Chicago: The University of Chicago Press, 1990, p. 1-17.

BOOIJ, G., RUBACH, J. Morphological and prosodic domains in lexical Phonology. Working papers in Linguistics, 14, 1984, p. 1-27.

BOOIJ, G., LIEBER, R. Morphological and prosodic structure. HARGUS, KAISSE

(Eds.) Studies in lexical Phonology, Academic Press, 1993, p. 23-44.

CAMARA Jr, M. Estrutura da Lingua Portuguesa. Petrópolis: Vozes, 1970.

FUDGE, E. Words and Feet. Journal of Linguistics 35, 1999: 273-296.

HALPERN, A. L. Clitics. In SPENCER, A., ZWICHY, A. M. (Eds.). The handbook of Morphology. Oxford: Blackwell, 1998, p. 101-122.

HAYES, B. The prosodic hierarchy in meter. In KIPARSKY, P., YOUMANS, G. (Eds.) Rhythm and meter. Orlando: Academic Press, 1989.

HARRIS, J. Syllable structure and stress in Spanish: a nonlinear analysis. Cambridge Mass: MIT, 1983.

KIPARSKI, P. On the lexical phonology of Icelandic. In: ELLERT, I.J., STRANGERT, E. (Eds.) Nordic Prosodic III, 1984, p. 135-164. 
LIBERMAN, M., PRINCE, A. On stress and linguistic rhythm. Linguistic Inquiry, 8, 1977, p.249-336.

MENUZZI, S., VIDOR, D. Pronomes como determinantes: algumas propriedades do elemento interrogativo que em Português. PUCRS, 1999. (Trabalho inédito).

NESPOR, M., VOGEL, I. Prosodic Phonology. Dordrecht: Foris Publications, 1986.

SCHWINDT, L. C. O prefixo no português brasileiro: análise morfofonológica. Porto Alegre: PUCRS, 2000.

SELKIRK, E. Phonology and Syntax. The relation between sound and structure. Cambridge: The Mit Press, 1984.

SELKIRK, E. On derived domains in sentence phonology. Phonology Yearbook 3, p. 371-405, 1986.

SELKIRK, E., SHEN, T. Prosodic domains jil the phrasal phonology. ln: INKELAS, S., ZEC, D. The Phonology-syntax connection. San Diego: Academic Press, 1990, p 313-337.

VIGÁRIO, M. On the prosodic status of stressless function words in European Portuguese. In: T. A. Hall and U. Kleinhez (eds.). Studies on the phonologial word. Amsterdam: John Benjamins, 1999: 225-294. [Comunicação apresentada na "Conference on the Phonological Word", Berlin, 1997].

ZEC, D. Rule domains and phonological change. In: HARGUS, S., KAISSE, E. Phonetics and Phonology. San Diego, Academic Press, 1992, p. 365-403. 